\title{
POLY(3-HYDROXYBUTYRATE-CO-3-HYDROXYVALERATE) BASED INORGANIC CONSOLIDATE FOR FIRWOOD PRESERVATION
}

\author{
Mădălina Elena DAVID ${ }^{1,2}$, Ramona Marina GRIGORESCU ${ }^{1}$, \\ Lorena IANCU ${ }^{1}$, Elena Ramona ANDREI ${ }^{1}$, Rodica-Mariana ION ${ }^{1,2}$ \\ 1 "Evaluation and Conservation of Cultural Heritage" Research Group, National Institute for Research and \\ Development in Chemistry and Petrochemistry, ICECHIM, 202 Splaiul Independentei, Bucharest, Romania \\ ${ }^{2}$ Materials Engineering Department, Valahia University, $13^{\text {th }}$ Aleey Sinaia, Targoviste, Romania \\ e-mail: madalina.e.david@gmail.com
}

\begin{abstract}
The aim of this study was to address one of the major challenges of the conservation state of wooden artifacts or artworks namely, the preservation and restoration of wood surfaces. The factors involved in the deterioration of wood are mainly the external factors such as fire, low temperature and microbiological agents, which induce some degradation processes in wood, identified by discoloration, fragility and unsightly appearance. In this study, biodegradable materials based on poly(3-hydroxybutyrate-co-3-hydroxyvalerate) (PHBHV) and composites based on PHBHV and particles (zinc oxide (ZnO), carbonated hydroxyapatite (CHAp) and its metallic derivatives with silver (AgCHAp) and strontium (SrCHAp) were applied on firwood specimens in order to investigate their consolidation capacity. Colorimetric measurements have confirmed that the chosen treatments did not change the colour of the natural wood. The hardness test revealed that the consolidation system increases the mechanical properties of the samples. The used treatments confer a strong hydrophobic character which prevents exfoliation of the wood samples, as confirmed by the performed water absorption test.
\end{abstract}

KEYWORDS: poly(3-hydroxybutyrate-co-3-hydroxyvalerate), zinc oxide, carbonated hydroxyapatite, preservation, firwood

\section{Introduction}

Wood is one of the oldest materials in the humanity history being used for thousands of years as a construction material, for furniture, fuel and paper. It is an organic material and presents a porous and fibrous structure which supports a continuous degradation and deterioration processes by weathering and various organisms' action $[1,2]$. Due to the hygroscopic nature of wood [3], this material is subjected frequently to several deterioration processes, like the loss of mechanical strength through moisture absorption, a higher degree of surface roughness and cracking on UV exposure [47], so the treatments that preserve the wood are highly needed.

In order to prevent the wood degradation processes, the researchers have tried to use some conservation treatments with different compatible materials [1, 8, 9]. In the last several years, biodegradable polymeric materials have been used in order to protect the wooden artifacts or artworks. Polyhydroxyalkanoates (PHAs) are a class of biodegradable polymers under ambient conditions that can be intracellularly synthesized by a range of bacteria and archaea from renewable/waste resources $[10,11]$. Among all the PHAs family, poly(3hydroxybutyrate) (PHB) and its copolymer poly(3hydroxybutyrate-co-3-hydroxyvalerate) (PHBHV) are the most common used in various applications and currently, these materials have been tested in order to investigate their potential in wood protection $[10,12]$. In the last years, PHBHV has received great attention from different research labs. For example, Chan C.M. and co-workers investigated the effects of natural weathering on the physical and mechanical properties of biodegradable composites based on PHBHV and wood flour (WF). Composite samples with three 
different WF contents $(0,20$ and $50 \mathrm{wt} \%)$ were placed on an outdoor inclined rack for 12 months. It was observed that neat PHBHV and the $20 \%$ WF samples showed little loss in mechanical properties over the 12-month period compared 50\% WF. A less dense fungal cell network and lower dry weight loss values were observed on the PHBHV 20\%WF composite when compared to $50 \% \mathrm{WF}$. At lower wood content, the PHBHV matrix acted as a barrier, partially encapsulating the wood particles. A lower relative abundance of fungi was shown in all PHBHV samples, suggesting that PHBHV does not promote fungal colonization relative to woody materials [10].

Also, in the last years it has been demonstrated that both micro and nanomaterials plays an important role in cultural heritage, new and efficient systems being obtained and successfully tested on wood, such as metallic oxides $\left(\mathrm{ZnO}, \mathrm{TiO}_{2}, \mathrm{CuO}\right)$ [13-16], metallic nanoparticles $(\mathrm{Ag})$ [17] and recently, hydroxyapatite (HAp) $\left(\mathrm{Ca}_{10}\left(\mathrm{PO}_{4}\right)_{6}(\mathrm{OH})_{2}: \mathrm{Ca} / \mathrm{P}=1.67\right)[1,18-20]$. By replacing the phosphate and/or the hydroxyl groups from the apatite structure with carbonate groups, carbonated hydroxyapatite can be obtained and its mechanical and antimicrobial properties can be enhanced by the insertion of metallic ions that replace calcium. With a similar structure compared with HAp and better characteristics, CHAp can improve the wood resistance to environmental impact [18].

This paper aims to obtain new composite coatings based on PHBHV and inorganic consolidants, such as $\mathrm{ZnO}$ micronized particles [16], carbonated hydroxyapatite (CHAp) and CHAp derivatives with different metal ions $\left(\mathrm{Ag}^{+}, \mathrm{Sr}^{2+}\right)$ [18]. The obtained solutions were tested on firwood samples, in order to investigate the potential of new solutions for artifacts preservation.

\section{Materials and methods}

\section{Wooden materials:}

In this study, firwood specimens $(7 \times 3 \times 1 \mathrm{~cm})$ without knots were treated by brushing three times on all sides with the solutions based on PHBHV and particles.

\section{Solutions preparation:}

PHBHV powder with a molecular weight of $67,000 \mathrm{~g} / \mathrm{mole}$ containing $2 \%$ hydroxyvalerate (Good Fellow) was used as composites matrix. A solution of PHBHV (1 wt \%) in chloroform was prepared by heating the solution for $6 \mathrm{~h}$ at $60{ }^{\circ} \mathrm{C}$ under magnetic stirring [21]. The PHBHV/ZnO solution was obtained according to Fig. 1.

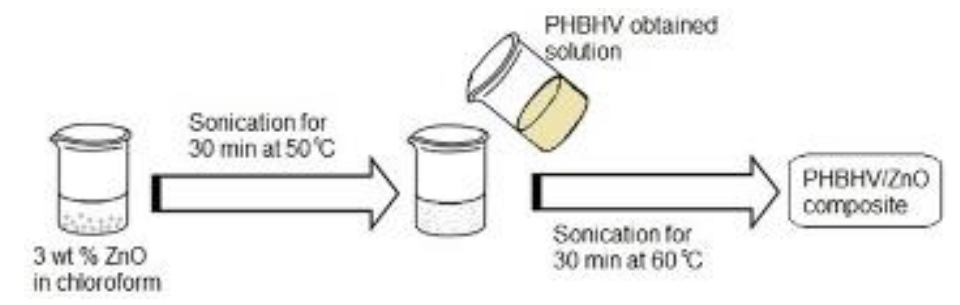

Fig. 1. Schematic diagram of the procedure for the preparation of the PHBHV/ZnO composite

CHAp and its metallic derivatives $(\mathrm{Ag}, \mathrm{Sr})$ nanoparticles (NPs) have been prepared by a nanoemulsion technique described in our previous study [18] and then used in order to obtain PHBHV/CHAp NPs, PHBHV/AgCHAp NPs and PHBHV/SrCHAp NPs solutions. The solutions were obtained in the same way as in the case of PHBHV/ZnO solution.

\section{Characterization methods}

Colorimetric Measurements have been recorded with a CR-410 colorimeter (Konica Minolta, Tokyo, Japan). The measurements were expressed following the CIE L* a* b* systems [22]. The total color differences $\Delta \mathrm{E}_{\text {xfinal }}$ was estimated according to $\mathrm{EN}$ 15886 [23] and ASTM 2244 [24], and calculated using formula (1).

$$
\Delta \mathrm{E}_{x f i n a l}=\left[\Delta \mathrm{L}^{2}+\Delta \mathrm{a}^{2}+\Delta \mathrm{b}^{2}\right]^{1 / 2}
$$

where, $\Delta \mathrm{L}$ is the difference in lightness $\left(\Delta \mathrm{L}=L_{\text {treated material }}-L_{\text {control }}\right), \quad \Delta \mathrm{a} \quad$ is the chromatic deviation of the a coordinates (ranges in value from +60 (red) to -60 (green), $\left.\Delta \mathrm{a}=a_{\text {treated material }}-a_{\text {control }}\right)$ and $\Delta \mathrm{b}$ is chromatic deviation of the $b$ coordinates (ranges in value from +60 (yellow) to -60 (blue), $\left.\Delta \mathrm{b}=b_{\text {treated material }}-b_{\text {control }}\right)$.

The colorimetric investigation has been recorded for the untreated and treated specimens with PHBHV, PHBHV / CHAp, PHBHV / AgCHAp, PHBHV / SrCHAp and PHBHV / ZnO solution applied by brushing on the surfaces of firwood specimens.

Gloss Measurements have been performed according to ISO 2813 [25] with 3nh glossmeter, model HG268. This technique has been used in order to investigate the specular reflection gloss of the 
surfaces. The glossmetric investigation was recorded for untreated and treated samples.

Mechanical Testing Measurements have been recorded with a Silver Schmidt Hammer Proceq test hammer, type L-0.735 Nm impact energy, according to ASTM C805 [26]. The strength range of the Silver Schmidt test hammer is from $10-100 \mathrm{~N} / \mathrm{mm}^{2}$. For each sample, ten replicates in different places were recorded with the hammer positioned at $90^{\circ}$ downward and the result (rebound number value) was calculated as the average of the readings.

Water Absorption Test offers information about the quantity of water absorbed by a material at room temperature. In the first step, all the samples have been dried in an oven for 8 hours at $40{ }^{\circ} \mathrm{C}$, this low drying temperature will prevent the deterioration of any organic substances employed in the case of treated samples. After drying, the samples were left at room temperature to cool, and then weighed (W1). Once being completely dried and the constant mass being recorded, the samples were placed in a tray filled with distilled water for 24 hours. Then the samples were removed from the water, wiped with a paper towel and weighed $\left(\mathrm{W}_{2}\right)$. The water absorption (WA) was calculated using formula (2).

$$
W A=\frac{W_{2}-W_{1}}{W_{1}}: 100
$$

Water Drop Absorption test measures the absorption time of a limited and definite amount of water by the surface of a material. In the first step, all the samples have been dried in an oven for 24 hours at $60{ }^{\circ} \mathrm{C}$, and then the samples were left at room temperature to cool. A burette (filled with distilled water) was placed at a distance of $1 \mathrm{~cm}$ from the sample surface and then $1 \mathrm{~mL}$ of water was dropped onto the surface of the sample. The time required for the total absorption of the water in the case of all samples was investigated.

\section{Results and discussion}

In order to investigate the ability of the new materials to consolidate the wood, the first step was to determinate the variation of chromatic parameters before and after the application of the treatment (Fig. 2 (a) and (b)). Chromatic parameters are important because the applied treatment must not significantly change the original colour of the object. Compared with Control (untreated wood) it can be observed that all the treated samples present very low differences in the case of $\Delta \mathrm{a}_{\mathrm{x}}$ coordinate, that indicated sample reddening (Fig. 2 (a)). In the yellow-blue interval $\left(\Delta b_{x}\right)$ some changes in colour can be observed (indicating yellowing), mostly in the case of the samples where particles are present, but these differences of colour are below 3, what means that the samples colour is stable. Also, the total colour differences $\Delta \mathrm{E}_{\mathrm{x}}$ confirms that the surface of the samples treated with PHBHV-ZnO and PHBHVAgCHAp are the most light in colour, due to the presence of the particles. These differences are acceptable because the values are below 3 what means that consolidate doesn't influence the colour of the samples. In the case of PHBHV-CHAp and PHBHV-SrCHAp, $\Delta \mathrm{E}_{\mathrm{x}}$ ranges from 1.5 to 3.0 , what means that the difference is barely noticeable on the surface, and for PHBHV the difference is slightly perceptible [27]. The graphic representation of the colour of the samples (Fig. 2 (b)) confirms that the closest colour to the control samples are the samples treated with PHBHV and PHBHV-CHAp.
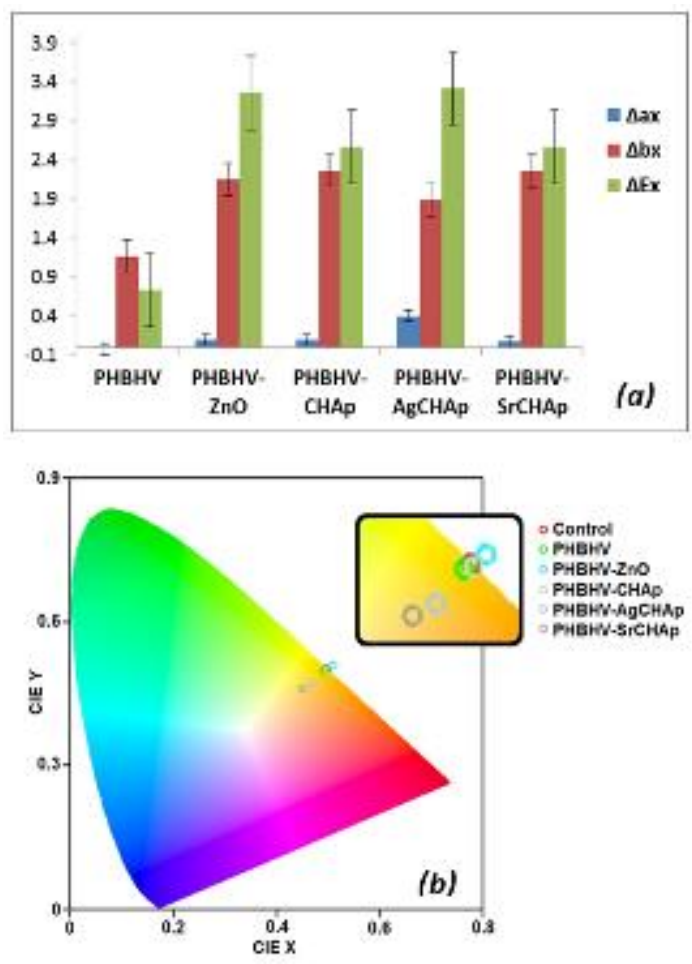

Fig. 2. Chromatic parameters (a) and graphic representation of the colour of the samples in the CIE 1931 system (b) of the untreated and treated samples

Gloss measurements (GU) were carried out in order to investigate the changes in the texture of the samples (changes in reflecting properties over the surface). It can be observed (Fig. 3) that all the samples presented a low gloss (values under 10 gloss units-GU), and when the treatment is applied the gloss of the sample present a small decrease, mostly in the case of the samples treated with the solution based on PHBHV-ZnO. 

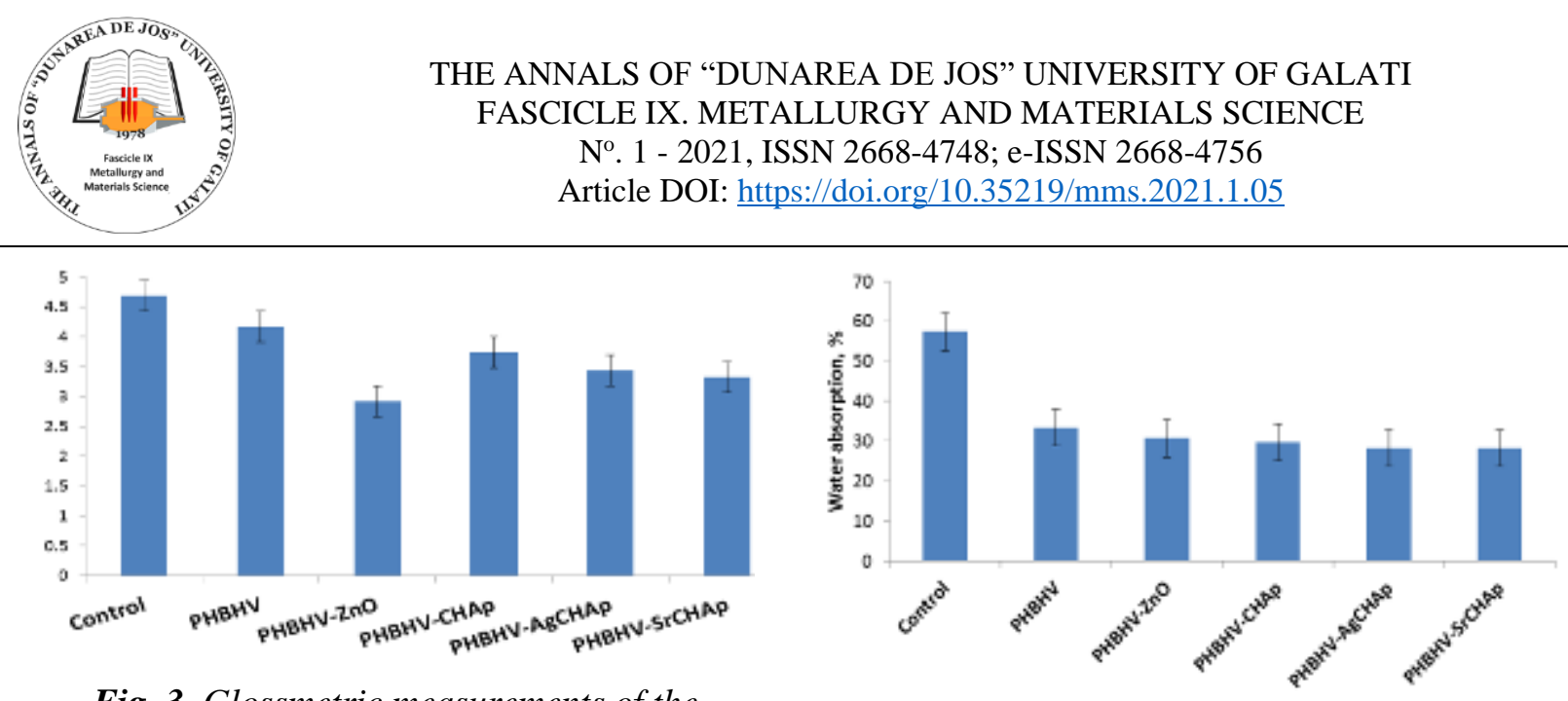

Fig. 3. Glossmetric measurements of the untreated and treated samples

Mechanical measurements were recording with Silver Schmidt test hammer in order to evaluate the mechanical properties of the wood samples. The rebound number measurements for the untreated and treated samples are shown in Fig. 4. Compared to control, all the treated samples presented an increased rebound number. The sample treated with PHBHVCHAp NPs presents the highest values. The addition of the particles on the samples surface enhanced the durability of wood compared to the untreated wood, due to the role of the particles in reinforcing the wood [1].

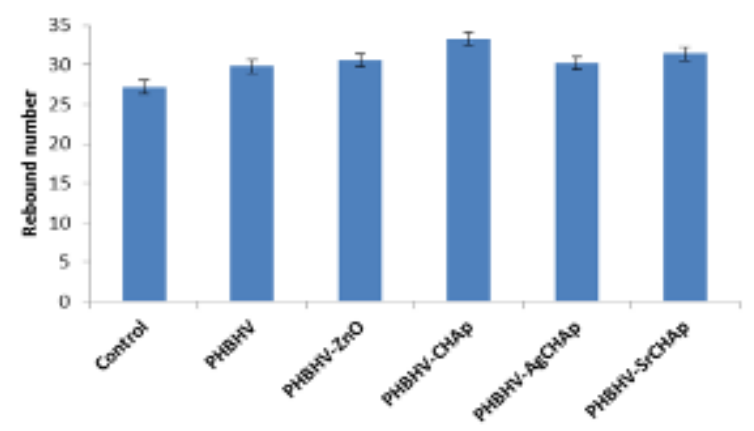

Fig. 4. Mechanical strength of the untreated and treated samples

Wood is a hydrophilic material and adsorbs moisture when it is exposed to real conditions. Water absorption test (Fig. 5) was carried out in order to investigate the quantity of water absorbed by a material under specified conditions. Compared with control it can be observed that the treated samples present a lower absorption capacity (the untreated sample has absorbed almost a double amount of water compared to treated samples), what proves the efficiently of the treatment.

Fig. 6 presents the aspect of untreated and treated sample, which confirms that treatment prevents exfoliation of the sample (a very common phenomenon in the case of wood found in nature). 
sample was completely dried (Fig. 7 - control). In the case of the treated materials, the drop remains on the wood surfaces until it evaporates, after 8 hours $\sim 70 \%$ of the drop was evaporated. After 24 hours, the drop was completely evaporated from the surface of the treated materials, so the treated samples maintained their hydrophobic character in time.

\section{Conclusions}

This study investigated the potential of biodegradable coatings based on PHBHV and particles, tested on the firwood samples, as a new solution for preservation of some wooden artifacts. The values obtained on colorimetric and gloss measurements have confirmed that all consolidates did not significantly influence the aspect of the samples. The hardness test reveals that the presence of the consolidating system increases the mechanical properties of the samples. The improvement of resistance was achieved for all the treated samples, mostly in the case of the samples treated with PHBHV-CHAp. The tests performed in order to investigate the absorption capacity of the samples confirmed that the used treatments confer a strong hydrophobic character to the samples, due to the fact that the drop was not absorbed by the material but evaporated in time from the surface samples. Also, by visual analysis it can be confirmed that the untreated sample presents a strong exfoliating behavior of the surface, compared to the treated sample. So, following these results it can be confirmed that the developed treatments for firwood protection are a good alternative to protect the wood-based materials found in nature.

\section{Acknowledgments}

This work was supported by a grant of the Romanian Ministry of Research and Innovation, CCCDI-UEFISCDI, project number PN-III-P1-1.2PCCDI-2017-0476/51PCCDI/2018, within PNCDI III.

\section{References}

[1]. Ion R.-M., Nyokong T., Nwahara N., Suica-Bunghez I.-R., Iancu L., Teodorescu S., Dulama I. D., Stirbescu R. M., Gheboianu A., Grigorescu R. M., Wood preservation with gold hydroxyapatite system, Heritage Science, 6(1), p. 37, 2018.

[2]. Laks P., Heiden P. A., Compositions and methods for wood preservation, Google Patents, 2003.

[3]. Stark N., Influence of moisture absorption on mechanical properties of wood flour-polypropylene composites, Journal of Thermoplastic Composite Materials, 14(5), p. 421-432, 2001.

[4]. Tajvidi M., Najafi S. K., Moteei N., Long-term water uptake behavior of natural fiber/polypropylene composites, Journal of Applied Polymer Science, 99(5), p. 2199-2203, 2006.
[5]. Badji C., Soccalingame L., Garay H., Bergeret A., Bénézet J.-C., Influence of weathering on visual and surface aspect of wood plastic composites: Correlation approach with mechanical properties and microstructure, Polymer Degradation and Stability, 137, p. 162-172, 2017.

[6]. Fabiyi J. S., McDonald A. G., Wolcott M. P., Griffiths P. R., Wood plastic composites weathering: Visual appearance and chemical changes, Polymer Degradation and Stability, 93(8), p. 1405-1414, 2008.

[7]. La Mantia F. P., Morreale M., Accelerated weathering of polypropylene/wood flour composites, Polymer Degradation and Stability, 93(7), p. 1252-1258, 2008.

[8]. Teng T.-J., Arip M. N. M., Sudesh K., Nemoikina A., Jalaludin Z., Ng E.-P., Lee H.-L., Conventional technology and nanotechnology in wood preservation: A review, BioResources, 13(4), p. 9220-9252, 2018.

[9]. Morrell J. J., Protection of wood-based materials, Handbook of Environmental Degradation of Materials, Elsevier, p. 343-368, 2018.

[10]. Chan C. M., Pratt S., Halley P., Richardson D., Werker A., Laycock B., Vandi L.-J., Mechanical and physical stability of polyhydroxyalkanoate (PHA)-based wood plastic composites (WPCs) under natural weathering, Polymer Testing, 73, p. 214221, 2019.

[11]. Grigore M. E., Grigorescu R. M., Iancu L., Ion R.-M., Zaharia C., Andrei E. R., Methods of synthesis, properties and biomedical applications of polyhydroxyalkanoates: a review, Journal of Biomaterials Science, Polymer Edition, 30(9), p. 695712, 2019.

[12]. Radu I. C., Hudita A., Zaharia C., Galateanu B., Iovu H., Tanasa E. V., Georgiana Nitu S., Ginghina O., Negrei C., Tsatsakis A., Velonia K., Shtilman M., Costache M., Poly(3hydroxybutyrate-CO-3-hydroxyvalerate) $\mathrm{PHBHV}$ biocompatible nanocarriers for 5-FU delivery targeting colorectal cancer, Drug Deliv., 26(1), p. 318-327, 2019.

[13]. Clausen C. A., Green F., Kartal S. N., Weatherability and leach resistance of wood impregnated with nano-zinc oxide, Nanoscale research letters, 5(9), p. 1464, 2010.

[14]. Rassam G., Abdi Y., Abdi A., Deposition of TiO2 nanoparticles on wood surfaces for UV and moisture protection, Journal of Experimental Nanoscience, 7(4), p. 468-476, 2012.

[15]. Shiny K., Sundararaj R., Mamatha N., Lingappa B., A new approach to wood protection: Preliminary study of biologically synthesized copper oxide nanoparticle formulation as an environmental friendly wood protectant against decay fungi and termites, Maderas. Ciencia y tecnología, (AHEAD), 2019.

[16]. David M. E., Ion R.-M., Andrei E. R., Grigorescu R. M., Iancu L., Filipescu M. I., Superhydrophobic Coatings Based on Cellulose Acetate for Pinewood Preservation, Journal of Science and Arts, 1(50), p. 171-182, 2020.

[17]. Borges C. C., Tonoli G. H. D., Cruz T. M., Duarte P. J., Junqueira T. A., Nanoparticles-Based Wood Preservatives: The Next Generation of Wood Protection?, Cerne, 24(4), p. 397-407, 2018.

[18]. Ion R.-M., Iancu L., Vasilievici G., Grigore M. E., Andrei R. E., Radu G.-I., Grigorescu R. M., Teodorescu S., Bucurica I. A., Ion M.-L., Ion-Substituted Carbonated Hydroxyapatite Coatings for Model Stone Samples, Coatings, 9(4), p. 231, 2019.

[19]. Iancu L., Ion R.-M., Grigorescu R. M., David M. E., Ghiurea M., Vasilievici G., Stirbescu R. M., Dulama I. D., Double Substituted Carbonated Hydroxyapatite for Stone Consolidation, Journal of Science and Arts, 3(52), p. 713-730, 2020.

[20]. Ion R. M., Iancu L., David M. E., Grigorescu R. M., Trica B., Somoghi R., Vasile S. F., Dulama I. D., Gheboianu A. I., Tincu S., Multi-Analytical Characterization of Corvins' CastleDeserted Tower, Construction Materials and Conservation Tests, Heritage, 3(3), p. 941-964, 2020.

[21]. Leimann F., Cardozo Filho L., Sayer C., Araújo P., Poly (3-hydroxybutyrate-co-3-hydroxyvalerate) nanoparticles prepared by a miniemulsion/solvent evaporation technique: effect of phbv 


\section{THE ANNALS OF “DUNAREA DE JOS" UNIVERSITY OF GALATI \\ FASCICLE IX. METALLURGY AND MATERIALS SCIENCE \\ $\mathrm{N}^{\circ} .1$ - 2021, ISSN 2668-4748; e-ISSN 2668-4756 \\ Article DOI: https://doi.org/10.35219/mms.2021.1.05}

molar mass and concentration, Brazilian Journal of Chemical Engineering, 30(2), p. 369-377, 2013.

[22]. Ion R.-M., Iancu L., Grigorescu R.-M., Tincu S. Vasilievici G., Ion N., Bucurica I. A., Teodorescu S., Dulama I. D., Stirbescu R. M., Arhaeometric investigations on ceramic materials from Hunedoara-the court area, Journal of Science and Arts, 18(2), p. 471-480, 2018.

[23]. ***, EN U 15886. Conservation of cultural property, Test methods. Colour measurements of surfaces, 2010.

[24]. ***, ASTM D 2244. Standard Practice for Calculation of Color Tolerances and Color Differences from Instrumentally Measured Color Coordinates, American Society for Testing and Materials, West Conshohocken, PA, 2003.
[25]. ***, ISO 2813: Paints and Varnishes-Determination of Gloss Value at 20 Degrees, 60 Degrees and 85 Degrees, International Organization for Standardization, 2014.

[26]. Aydin F., Saribiyik M., Correlation between Schmidt Hammer and destructive compressions testing for concretes in existing buildings, Scientific Research and Essays, 5(13), p. 1644$1648,2010$.

[27]. Garay R., Inostroza M., Ducaud A., Color and gloss evaluation in decorative stain applied to cases of Pinus radiata wood treated with copper azole micronized Type $C$, Maderas. Ciencia y tecnología, 19(1), p. 21-38, 2017. 